\title{
Índice de inestabilidad política del Brasil, 1889-2009
}

\author{
Jaime Jordan Costantini y Mauricio Vaz Lobo Bittencourt
}

RESUMEN

Este artículo tiene como objetivo la elaboración de un índice de inestabilidad política (INS) del Brasil entre 1889 y 2009. Dicho índice refleja un conjunto amplio de múltiples fenómenos que representan conflictos entre los diversos grupos sociales. Por medio de la presentación de diferentes definiciones de lo que se entiende por inestabilidad política en la bibliografía económica y mediante la utilización de múltiples acontecimientos históricos — golpes de Estado, conflictos civiles, destituciones constitucionales o inconstitucionales y cambios en la composición del 50\% del gabinete de ministros - se obtienen distintos indicadores que se reducen a uno solo gracias a la técnica del componente principal, para obtener así un INS del Brasil en el período comprendido entre 1889 y 2009. y Desarrollo Económico (NeIde) de la Universidad Federal de Paraná (UfPR), Brasil. jordan_costantini@ hotmail.com

Mauricio Vaz Lobo Bittencourt es profesor del Programa de Posgrado en Desarrollo Económico de la Universidad Federal de Paraná (UfPR), Brasil. mbittencourt@ufpr.br 


\section{I}

\section{Introducción}

Para comprender mejor el proceso de desarrollo económico de los países, en la bibliografía económica, en general, se utilizan modelos teóricos y empíricos que no incluyen una definición clara del significativo rol que desempeña la inestabilidad política en ese proceso de desarrollo. Además, a menudo no se tiene en cuenta el papel histórico de la inestabilidad y los estudios empíricos se basan en presupuestos del tipo ceteris paribus para analizar sus resultados.

Resulta extremadamente conveniente no solo establecer formas de aumentar el nivel de realismo de los estudios sobre la economía del desarrollo, sino también prestar un mayor apoyo a los análisis empíricos que se realicen, mediante modelos teóricos, empíricos y datos que llenen esos vacíos, especialmente la dificultad para incluir en esos análisis las variables institucionales e históricas. Estas variables pueden manifestarse en la estabilidad —o inestabilidad- política de los países, que solo son un reflejo de los procesos de cambio de las instituciones a lo largo del tiempo, procesos que a su vez influyen en las variables económicas y son influidos por ellas.

Existe un gran interés entre los economistas en comprender las relaciones entre inestabilidad política y actividad económica de los países. Hay muchas investigaciones teóricas y empíricas sobre los efectos económicos de la inestabilidad y los principales trabajos pueden resumirse en tres enfoques.

En el primer enfoque se estudian los efectos de la inestabilidad política en la economía, sobre la base de explicar los ciclos de la política fiscal. En este ámbito, las contribuciones más destacadas son las de Rogoff y Sibert (1988); Alesina y otros (1992); Alesina y Tabellini (1990); Edwards y Tabellini (1991); Cukierman, Edwards y Tabellini (1992), y Bohn (2003). En estos trabajos se destacan tres efectos principales de la inestabilidad política en la economía: i) dicha inestabilidad genera políticas públicas subóptimas, en la medida en que los encargados de la formulación de políticas afrontan incertidumbres sobre su propia permanencia en el gobierno y manipulan la macroeconomía como una herramienta de la lucha por el poder; ii) las decisiones de inversión de los emprendedores sufren la influencia negativa de un clima de inestabilidad política en el que los gobiernos implementan políticas subóptimas, y iii) tal inestabilidad provoca interrupciones de la producción, lo que reduce la productividad total de los factores (PTF).

En el segundo enfoque se investigan las relaciones de la inestabilidad política con el crecimiento económico. Para ello, se requiere modelar los conflictos de poder de las clases sociales y sus efectos en la acumulación de capital. A esta área corresponden los trabajos de Annett (2001); Devereux y Wen (1998), y Woo (2005), que estudian, desde el punto de vista de la teoría económica, los efectos de los conflictos de poder en sociedades desiguales y polarizadas o divididas étnicamente.

El tercer enfoque se refiere a trabajos empíricos. Entre las investigaciones fundamentales se encuentran las de Barro (1991 y 1996), que utilizó muestras de países con las técnicas de paneles de datos para estudiar los efectos de la inestabilidad política en el crecimiento económico. En diversos estudios recientes se utiliza el método de momentos generalizados (GMM por sus siglas en inglés) para lidiar con los problemas de endogeneidad, como en el trabajo de Aisen y Veiga (2011), quienes intentan determinar a través de cuáles canales se manifiesta la inestabilidad política en la estructura económica.

Otros estudios empíricos son de tipo regional y en ellos se investiga el tema en relación con un conjunto de países. Entre los principales trabajos de este tipo destaca el de Solimano (2003), que analizó la inestabilidad política en los países andinos utilizando diferentes variables (cambio de Constitución, crisis presidenciales y volatilidad de la democracia) que explican el desempeño deficiente de sus instituciones. También existen estudios de ámbito nacional, entre los que destacan el de Evia, Laserna y Skaperdas (2008) respecto de los efectos de las protestas sociales en la economía boliviana, que provocaron una reducción del producto en varios puntos porcentuales, y el de Muñoz (2009), que estableció que, en el caso de Venezuela (República Bolivariana de), la inestabilidad política es una de las principales causas de la tendencia a la baja de la actividad económica.

El objetivo del presente trabajo es llenar algunas de los vacíos señalados anteriormente mediante la elaboración de un índice de inestabilidad política (INS) del Brasil entre los años 1889 y 2009. Disponer de un índice de este tipo permitirá realizar un análisis de las principales tendencias de la inestabilidad política en la 
historia del Brasil y relacionar los fenómenos políticos con los del ámbito estrictamente económico. El índice podría utilizarse en diversos estudios futuros para comprender mejor el proceso de desarrollo brasileño, ya que contempla las dimensiones política, social, histórica e institucional, además de la económica.

Este artículo está organizado en seis secciones, incluida la Introducción. En la segunda sección se discuten las diferentes definiciones de inestabilidad política y los métodos apropiados para medirla. En la sección III se presenta el contexto histórico de la inestabilidad política en el Brasil y en la IV, la metodología utilizada. En la quinta sección se incluyen los resultados y la serie de inestabilidad política del Brasil entre 1898 y 2009 , mientras que la última sección contiene las consideraciones finales del artículo.

\section{II}

\section{¿Qué se entiende por inestabilidad política?}

En la bibliografía relacionada existen dos definiciones de inestabilidad política. En la primera de ellas se concibe dicha inestabilidad como la propensión a cambiar el gobierno antes del fin de su mandato legal, mediante mecanismos constitucionales o inconstitucionales. Esta definición es la aplicada por Cukierman, Edwards y Tabellini (1992).

En la segunda definición, utilizada por Annett (2001) y Aisen y Veiga (2011), entre otros, se establece que la inestabilidad política es el resultado de un conjunto de múltiples fenómenos que representan conflictos entre los diferentes grupos sociales. Esos fenómenos pueden ser guerras civiles, golpes de Estado, protestas violentas, nuevas constituciones u otros. Por regla general, esas variables se miden como variables categóricas. Esta definición de inestabilidad política representa mejor la evolución política de un país, porque refleja un proceso complejo, determinado por un conjunto amplio y diverso de fenómenos que influyen en esa inestabilidad.

A menudo, los episodios de inestabilidad política en el Brasil están vinculados a cambios sociales y políticos, como ocurre con la llamada Era Vargas. En esos casos, los elementos de la inestabilidad política se relacionan con un conjunto variado de múltiples fenómenos políticos y sociales y, por lo tanto, es más apropiado utilizar la segunda definición de inestabilidad política.

Cuando la inestabilidad política se relaciona con múltiples factores, deben aplicarse técnicas estadísticas para obtener una variable única que represente la inestabilidad política del conjunto de tales factores. La técnica estadística adecuada para ese fin es el método de componente principal, aplicado por Annett (2001) y Aisen y Veiga (2011).

\section{III}

\section{Contexto histórico de inestabilidad política en el Brasil entre 1889 y 2009}

Al terminar el siglo XIX, el colonialismo portugués había dejado cuatro herencias organizativas que resultarían muy persistentes y que caracterizarían el perfil de las instituciones en el Brasil:

i) $\mathrm{Al}$ delegar significativas funciones a los poderes locales (Fausto, 1996), el pragmatismo del poder colonial siguió presente en el Imperio del Brasil.
La Constitución del 24 de febrero de 1822, en su artículo 66, autorizaba expresamente a los estados para obtener créditos, organizar fuerzas militares propias y decretar impuestos sobre la exportación de sus mercancías.

ii) Una gran concentración de la propiedad de la tierra, estructurada en grandes extensiones, institución 
que se originó en el colonialismo tardío ${ }^{1}$ de las capitanías hereditarias y sesmarías o concesiones de tierras a los colonos ${ }^{2}$.

iii) El colonialismo y el mercantilismo configuraron la inserción internacional del Brasil. Las colonias debían contribuir a la economía de la metrópoli en áreas determinadas, con exclusión de otros poderes coloniales $^{3}$. Los excedentes para la exportación provenían del trabajo forzoso de los indígenas y, posteriormente, de la esclavitud de los negros. Los ciclos del mercantilismo estuvieron relacionados con ciertas regiones del Brasil y con determinados productos para la exportación, como el Pernambuco (en el siglo XVI), la exportación de azúcar en el nordeste (en el siglo XVI, con apoyo de los Países Bajos), o el oro y los diamantes en el estado de Minas Gerais (en los siglos XVII y XVIII, como desarrollo clave para Portugal $)^{4}$. Otros productos primarios (tabaco y caucho) se convirtieron en cultivos alternativos. A mediados del siglo XIX comenzó la producción de café, inicialmente en Río de Janeiro y posteriormente en São Paulo, que daría lugar a grandes transformaciones en el Brasil.

iv) Una tradición de trabajo forzado de indios y negros que finalizó en 1880, de modo que las élites de poder brasileñas tuvieron que fomentar la inmigración de extranjeros para el cultivo del café. Según Madisson (2008), entre 1880 y 1913 llegaron al Brasil 2,7 millones de extranjeros (la mitad italianos, 700.000 portugueses y 400.000 españoles, además de cantidades menores de otras nacionalidades). Para un país que, a comienzos del siglo XX tenía 17 millones de habitantes, esas cifras migratorias resultan altamente significativas.

\footnotetext{
${ }^{1}$ Según Fausto (1996, págs. 24-26), a pesar de que el descubrimiento del Brasil por Pedro Álvarez Cabral se produjo en 1500, la colonización propiamente dicha comenzó en 1549 y se consolidó en 1763 con la fundación de la primera capital en la ciudad de Salvador, Bahia.

${ }^{2}$ La creación de las sesmarías dio origen a los latifundios o haciendas, que concentraban el poder político, y a una clase dirigente del ámbito económico, lo que tendría efectos duraderos en el Brasil.

${ }^{3}$ En el caso del Brasil, la exclusividad colonial no fue tan marcada debido a la imposibilidad de imponerla y al hecho de que los centros de comercio estaban fuera de Portugal. En el siglo XVI, los Países Bajos participaron en el usufructo colonial y, en el siglo XVII, Inglaterra también se incorporó al esquema colonial.

${ }^{4}$ El déficit comercial de Portugal con Inglaterra se pagó con el oro que venía de Minas Gerais.
}

\section{La Primera República y el pacto oligárquico entre 1889 y 1929}

La concentración de la propiedad de la tierra, la presencia de una fuerza de trabajo inmigrante calificada y las oportunidades para la producción de café en São Paulo contribuyeron al deseo de establecer una estructura de poder político propicia para los intereses de las élites del poder. Otro antecedente fue la nueva Constitución liberal de 1891, que otorgaba autonomía a los estados con respecto al poder federal, lo que permitiría tomar medidas de valorización del café, algo que fue fundamental para el estado de São Paulo.

El eje del pacto oligárquico entre las élites políticas consistía en el café y la expansión del mundo urbano en São Paulo, Río de Janeiro, Belo Horizonte, Bahia y Porto Alegre. Políticamente, las élites de Minas Gerais y de São Paulo iban alternándose en el ejercicio del poder nacional a través de la llamada "política del café con leche".

El significativo peso que tenían los intereses de los cafeteros en la definición de la política económica de la época se tradujo en una orientación económica no ortodoxa de los asuntos públicos, debido a los efectos expansivos en los gastos públicos de las políticas de defensa del precio del café. Sin embargo, los banqueros internacionales que participaban en el plan de defensa del precio del café exigían un mayor rigor en la administración de los recursos públicos que garantizase la solvencia de los créditos. Además, los estados no participantes en el pacto oligárquico tenían intereses diferentes de los de los cafeteros del estado de São Paulo. En consecuencia, durante ese período, las políticas económicas no ortodoxas se alternaron con otras de cuño más liberal, dada la preocupación por el equilibrio fiscal, la inflación y la viabilidad de la balanza de pagos.

La gestión del pacto oligárquico se fue haciendo más compleja debido a la aparición de problemas tanto económicos como políticos. El problema económico más destacado fue la crisis de 1929, que tuvo efecto en dos frentes. A partir de 1926, el Brasil encontró problemas para obtener los créditos externos necesarios para mantener el precio del café, a causa de las políticas restrictivas que se habían implementado en los Estados Unidos de América con el objeto de controlar la burbuja especulativa de Wall Street. En 1932, los precios del café eran un $30 \%$ inferiores a los de 1929 y el café representaba cerca del $70 \%$ de las exportaciones del Brasil. El problema político fue la ruptura del pacto oligárquico, que permitió que el líder del estado de Rio Grande do Sul, Getúlio Vargas, tomara el poder con un golpe de Estado militar. 


\section{Transformaciones económicas entre 1930 y 1964}

En 1930, bajo la dirección de Vargas, comenzaron a realizarse reformas en la organización política del Brasil, las que durarían 15 años. El elemento fundamental de estas reformas fue la centralización del poder gubernamental, que puso fin al alto grado de autonomía de los estados. Las reformas provocaron conflictos que llevaron al estallido de la Revolución Constitucionalista (o Guerra Paulista) de 1932. Se reformó la estructura del Estado con una ampliación de su esfera de actuación en la economía y se crearon numerosas instituciones públicas. Con las nuevas leyes se reconocieron más ampliamente los derechos de los trabajadores y se instituyó un salario mínimo, pero se restringió fuertemente el derecho a la huelga. Se destacó el papel de la industria en la economía con la creación de la Compañía Siderúrgica Nacional en Volta Redonda y de instrumentos de fomento de la industrialización a través del Banco de Desarrollo del Brasil (BNDES). Bajo el gobierno autoritario de Getúlio Vargas entre 1937 y 1945, en el Brasil se consolidaron las transformaciones que tendrían efectos duraderos en el país. Durante la Segunda Guerra Mundial, a causa de las dificultades de abastecimiento de bienes y materias primas procedentes del exterior, las condiciones fueron propicias para una política de sustitución de importaciones, que contribuyó a la modernización del país.

Con el fin del gobierno de Vargas, se inició la Tercera República y el período de democracias populistas desde 1945 a 1964. Durante ese tiempo, el legado de Vargas se consolidó mediante políticas en pro de la industrialización, con un decidido apoyo estatal. Entre 1945 y 1961, se registró un alto crecimiento económico, favorecido por un contexto internacional positivo (Abreu, 2000). Las tendencias económicas cambiaron ${ }^{5}$ durante el gobierno de João Goulart (1962-64) y en ese período se dieron diversos problemas políticos, que finalmente terminaron con el golpe militar de marzo de 1964.

\section{Gobierno militar entre 1964 y 1985}

El contexto histórico de los diferentes gobiernos que se sucedieron en el poder entre 1964 y 1985 puede dividirse en tres etapas: i) la primera etapa, entre 1964 y 1967, se

\footnotetext{
5 El producto interno bruto (PIB) creció un 8,6\% en 1961, pero en 1963 su crecimiento fue del 0,63\% y el producto industrial registró una tasa negativa de crecimiento del $-0,2 \%$. La inflación, medida por el Índice General de Precios-Disponibilidades Internas (IGP-DI)/ Fundación Getúlio Vargas (FGV), fue del 30,5\% en 1960, del 47,8\% en 1961 y alcanzó al 92,1\% en 1964.
}

caracterizó por el intento de alcanzar equilibrios básicos en la economía (principalmente de la inflación); ii) el período del milagro económico, desde 1967 hasta 1979, y iii) un período de estancamiento entre 1979 y 1985.

El Programa de Acción Económica del Gobierno (PAEG), entre 1964 y 1967, fue un plan de control de la inflación para corregir los desequilibrios de la balanza de pagos. Durante esos años se fue controlando la inflación de forma gradual, con una moderada expansión del PIB. En los años del milagro económico, desde 1967 hasta 1979, el PIB per cápita creció un 6,2\% anual, a pesar de las limitaciones debidas a problemas externos causados por el aumento de los precios del petróleo y el agravamiento de la situación a partir de 1982, cuando las altas tasas de interés internacionales dificultaron el financiamiento del déficit en la balanza de pagos. Durante este período, los profundos desequilibrios internos se unieron a una alta inflación interna y la percepción de fragilidad de las alianzas que sustentaban políticamente el ejercicio del poder por parte de los militares. Como respuesta política, se inició un largo proceso de transición a la democracia a partir del gobierno del Presidente Geisel, en 1979, que culminaría con la entrega del poder a los civiles en un sistema electoral indirecto por parte del último presidente militar, João Baptista Figueiredo, en 1985.

\section{Gobierno democrático a partir de 1985}

La transición a la democracia fue un proceso complejo y largo, debido a la existencia de al menos tres desafíos que formaron parte de los temas incluidos en la agenda política. El problema económico era uno de ellos y aparecía como el más urgente. El segundo era la necesidad sentida por importantes segmentos de la sociedad de una nueva Constitución que sustituyese a la existente, cuyas claras características autoritarias eran herencia de los gobiernos militares. El tercer desafío era enfrentar la pesada deuda social en términos de distribución de los ingresos que había dejado la política económica aplicada en las dos décadas de poder militar, deuda que debía abordarse para corregir los ásperos contornos de la realidad social del Brasil. Cabe resaltar que la clase obrera tuvo un papel significativo en el impulso del proceso democrático, gracias a su alto grado de organización y poder, que no podía ser ignorado por la clase política brasileña.

El sistema político brasileño en 1985, pese a estar integrado por los principales liderazgos y poderes políticos del país y de contar con instituciones democráticas, no consiguió lidiar rápidamente con esos tres desafíos de forma simultánea. Describir las trayectorias de las 
soluciones implementadas con respecto a cada desafío escapa al ámbito de este artículo, pero se presentan como epílogos las soluciones finalmente adoptadas por la sociedad brasileña.

En 1988 se aprobó una nueva Constitución de tipo democrático, que recuperó el legado de la Era Vargas. Se otorgó un papel importante al Estado en la economía y en la sociedad y se establecieron criterios de equidad relativos al género, los ingresos y las diferencias regionales.

La solución de los problemas económicos tuvo una larga y tortuosa trayectoria, hasta que luego de seis planes económicos de estabilización que fracasaron, el Brasil encontró en 1994, con el Plan Real, el camino para solucionar el problema inflacionario. Esa solución se consolidó, finalmente, durante el segundo mandato

\section{IV}

\section{Metodología}

La metodología aplicada incluye la definición de las variables, las fuentes de información, las bases de datos resultantes y las técnicas estadísticas utilizadas para sintetizar en un solo índice la inestabilidad política en el Brasil.

\section{Definición de las variables}

La inestabilidad política se mide por medio de una serie de indicadores y, por lo tanto, se considera que hay inestabilidad política en un año específico si se cumple alguna de las siguientes condiciones:

i) Interrupción del mandato constitucional del Presidente $(n c)$. En un año cualquiera, el mandato constitucional no se cumple, por dimisión, constitucional o no, del Presidente de la República. En esta situación, el presidente electo no llega a tomar posesión a causa de un acto inconstitucional $\mathrm{u}$ otro acontecimiento. Se produce cuando el presidente electo muere antes de tomar posesión, existe un hecho de fuerza mayor que le impide asumir el poder o no completa su mandato a causa de un golpe de Estado.

ii) Un cambio del 50\% del gabinete ministerial $(\mathrm{mg})$. Esta variable consiste en el número de veces al año que el jefe del Poder Ejecutivo cambia el 50\% del gabinete ministerial.

iii) Cambio de la Constitución $(m c)$. Debido a la aprobación de una nueva Constitución o de reformas constitucionales. del Presidente Fernando Henrique Cardoso. No obstante, incluso con la democracia, no se observó una tasa satisfactoria de crecimiento del producto, ya que —entre 1980 y 2008 - la tasa de crecimiento del PIB per cápita fue solo del $0,77 \%$, lo que indica la presencia de obstáculos para un alto crecimiento del Brasil.

En el plano social, se observaron avances significativos gracias a las políticas gubernamentales que redujeron la pobreza extrema, pero los avances en la distribución de los ingresos fueron limitados y las políticas públicas aún tienen un largo trecho por recorrer. También es necesario realizar grandes inversiones en las áreas de la salud, la educación, la infraestructura y la seguridad, y persiste la necesidad histórica de realizar reformas tanto en el sistema político como en el tributario.

iv) Guerras civiles o actos organizados de violencia con fines políticos $(g c)$. Se considera que la violencia es organizada si en ella participan más de 100 ciudadanos. Se trata de una variable medida dicotómicamente, cuyos valores son $g c=1$ cuando hay una guerra civil, actos de violencia o fuerzas militares irregulares y $g c=0$ en caso contrario.

v) Movimiento huelguista (greve). Se mide como el número de huelgas, normalizado en el intervalo $[0,1]$. En este artículo se presenta una innovación de esta variable en relación con los principales índices conocidos, que - como regla generalse basan en el número de huelgas políticas. Esta innovación se basa en el hecho de que el Brasil experimentó durante muchos años una limitación de los derechos de los trabajadores (durante la Era Vargas desde 1937 y, en tiempos recientes, entre 1964 y 1973). Después de esos períodos hubo una gran cantidad de movimientos huelguistas en los que no resulta fácil diferenciar los factores políticos y económicos.

Para determinar el valor de los cinco indicadores anteriores, se necesita información sobre los mandatos constitucionales, la toma de posesión de los presidentes electos, los cambios de gabinete, la aprobación de nuevas constituciones y la reforma de las existentes, las guerras civiles y el número de huelgas. En la sección de anexos se incluye una lista detallada de las fuentes de información utilizadas. 


\section{Conceptos básicos de la técnica de componente principal (CP)}

A partir de los datos de las variables definidas anteriormente ( $n c, m g, m c, g c$ y greve), se aplica la técnica multivariada de componente principal (CP) para obtener un vector único de la inestabilidad política del Brasil en el período 1889-2009.

Según Gurmu, Rilstone y Stern (1999), la técnica de CP es un enfoque de estadística multivariada que reduce un número amplio de variables a un menor número de dimensiones. Resulta especialmente útil cuando las variables consideradas están correlacionadas. El método de CP crea índices no correlacionados. Desde el punto de vista matemático, con un conjunto inicial de $n$ variables correlacionadas, el cP crea componentes no correlacionados, cada uno de los cuales consiste en una combinación lineal ponderada de las variables iniciales. Por ejemplo, para un conjunto de variables $X_{1}, \ldots \ldots, X_{n}$, se determinan los siguientes componentes:

$$
\begin{aligned}
& C P_{1}=a_{11} X_{1}+a_{12} X_{2}+\ldots+a_{1 n} X_{n} \\
& C P_{2}=a_{21} X_{1}+a_{22} X_{2}+\ldots+a_{2 n} X_{n} \\
& C P_{n}=a_{n 1} X_{1}+a_{n 2} X_{2}+\ldots+a_{n n} X_{n}
\end{aligned}
$$

donde $a_{m n}$ representa la ponderación del componente $m$ principal de la variable $n$. La ponderación de cada CP está dada por el autovector de la matriz de correlaciones si los datos originales están normalizados. La varianza

\section{V}

\section{Resultados}

En esta sección se presentan las estadísticas descriptivas de la base de datos utilizada, los análisis de los resultados del componente principal y, finalmente, un análisis del comportamiento de la inestabilidad política brasileña.

\section{Estadísticas descriptivas}

Los resultados incluyen la elaboración de la matriz de los valores de las variables para todos los años considerados (véase el anexo A.6). Un indicador ilustrativo para analizar las relaciones entre los indicadores utilizados es la matriz de correlaciones del cuadro 1. de cada CP es el autovalor correspondiente de cada autovector. Los componentes se ordenan desde el primer componente $\mathrm{CP}_{1}(1)$, que explica la mayor parte del valor original, sujeto a la restricción de que la suma de los cuadrados de las ponderaciones sea igual a uno, es decir, $a_{11}^{2}+a_{12}^{2} \ldots+a_{1 n}^{2}=1$. El segundo componente principal $\mathrm{CP}_{2}(2)$, explica una menor proporción de la variación del valor original y no está correlacionado con el (1). Cada CP captura una menor proporción del principal. De esta forma se puede reducir a un índice, utilizando como ponderador los autovalores del autovector correspondiente.

Técnicamente, como el CP describe un conjunto de variables con otro conjunto de variables de menor dimensión, el método identifica " $n$ " combinaciones lineales de las " $\mathrm{n}$ " columnas de la matriz $X^{T} X\left(X^{T}\right.$ es la matriz traspuesta), mutuamente ortogonales, con la propiedad de que el primer componente principal $p_{1}$ minimiza $\operatorname{tr}\left(X-p_{1} a_{1}\right)^{T}\left(X-a_{1} p_{1}\right)$, donde $\operatorname{tr}$ significa traza y $a_{1}$ es el autovector de $X^{T} X$ asociado al autovalor. El segundo componente principal $p_{2}$ resulta de minimizar $\operatorname{tr}\left(X-p_{1} a_{1}-p_{2} a_{2}\right)^{T}\left(X-a_{1} p_{1}-p_{2} a_{2}\right)$, donde $a_{2}$ es el autovector asociado al segundo autovalor. Este segundo componente representa los factores que no están representados por el primero. Siguiendo esta lógica, cada CP captura la varianza del anterior, que estará representada por su autovalor. Se puede demostrar que la contribución a la reducción de la variabilidad del CP es $\operatorname{tr}(X)^{T}(X)-\delta_{1}$, donde $\delta_{1}$ es el autovalor más alto.

En la sección siguiente se presenta la aplicación y el análisis de esa técnica para producir un indicador de inestabilidad política para el Brasil.

Los datos muestran una significativa correlación positiva entre la interrupción del mandato constitucional $(n c)$ y el cambio de Constitución $(m c)$. Este resultado puede indicar que la transformación de las constituciones existentes y la creación de nuevas constituciones en el Brasil fueron precedidas por cambios del gobierno al margen de un mandato legal. Esta correlación podría suponer que las reformas de las constituciones se entienden como actos de creación de un nuevo orden, a consecuencia de movimientos políticos que utilizan la fuerza. La gran excepción de esta afirmación es la Constitución de 1988. Existe una correlación negativa 
entre episodios de violencia organizada $(g c)$ y las huelgas (greve). Como ya se ha indicado, las huelgas tendían a ser recurrentes cuando los derechos de los trabajadores no existían plenamente en los períodos anteriores.

CUADRO 1

Brasil: matriz de correlaciones entre las variables relacionadas con la inestabilidad política, 1889-2009

\begin{tabular}{lrrrcc}
\hline & $m g$ & $n c$ & $m c$ & $g c$ & greve \\
\hline$m g^{\mathrm{a}}$ & 1 & & & & \\
$n c^{\mathrm{b}}$ & 0,0065 & 1 & & & \\
$m c^{\mathrm{c}}$ & 0,1587 & 0,3115 & 1 & & \\
$g c^{\mathrm{d}}$ & $-0,0038$ & $-0,0804$ & 0,1059 & 1 & \\
greve $^{\mathrm{e}}$ & 0,1608 & 0,0252 & $-0,0901$ & $-0,2416$ & 1 \\
\hline
\end{tabular}

Fuente: elaboración propia.

Nota: el número total de observaciones es de 120 y el nivel de significación es del 5\%.

a $m g$ indica los cambios del $50 \%$ en la composición del gabinete ministerial.

b $n c$ se refiere a la interrupción del mandato constitucional del Presidente.

c $m c$ refleja los cambios de la Constitución.

d $g c$ hace referencia a las guerras civiles y actos organizados de violencia.

e greve hace referencia a las huelgas.

En el cuadro 2 se presentan los resultados de la aplicación del método de los componentes principales (CP) en términos de la descomposición de los autovalores y autovectores. Los autovectores se ofrecen en su forma ortonormal, no correlacionados y normalizados, con una dimensión compatible con las cinco variables utilizadas.

Se puede observar que el $\mathrm{CP}_{1}$ explica una mayor proporción de la varianza en la muestra. Desde el punto de vista de los autovectores, las variables más importantes son: la creación de nuevas constituciones y reformas constitucionales y la interrupción de los mandatos constitucionales.

Para obtener el índice de inestabilidad política (INS), se utiliza el primer componente principal, lo que da lugar al siguiente sistema:

$$
\begin{gathered}
\text { INS }=0,2781 * m g+0,5982 * n c+0,7260 * m c+ \\
0,1712 * g c-0,1352 * \text { greve }
\end{gathered}
$$

Del resultado de las estimaciones se obtiene, para cada año, un INs (véase cuadro A.6).

En el gráfico 1 se aprecia la evolución de este índice entre 1889 y 2009.

En el gráfico 1 se presenta el INs del Brasil entre 1889 y 2009. Cuanto mayor es el valor de la ordenada, mayor es la inestabilidad política. El INs fue suavizado a través de la media móvil de tres años para identificar las grandes tendencias de la inestabilidad política en el Brasil, destacándose los períodos de alta inestabilidad.

El análisis del gráfico 1 permite afirmar que el Brasil tuvo períodos de alta inestabilidad política y se puede observar que esos años no fueron predominantes en la historia brasileña.

CUADRO 2

Brasil: correlación de los componentes principales de la inestabilidad política, 1889-2009

\begin{tabular}{lcccc}
\hline Componente & Autovalor & Diferencia & Proporción & Acumulado \\
\hline Componente 1 & 1,35551 & 0,04836 & 0,27110 & 0,27110 \\
Componente 2 & 1,30714 & 0,27947 & 0,26140 & 0,53250 \\
Componente 3 & 1,02768 & 0,31784 & 0,20550 & 0,73800 \\
Componente 4 & 0,70984 & 0,11000 & 0,14200 & 0,88000 \\
Componente 5 & 0,59983 & - & 0,12000 & 1,00000
\end{tabular}

Componentes principales (autovectores)

\begin{tabular}{lcrrrr}
\hline Variable & $\mathrm{CP}_{1}$ & $\mathrm{CP}_{2}$ & $\mathrm{CP}_{3}$ & $\mathrm{CP}_{4}$ & $\mathrm{NP}_{5}$ \\
\hline$m g^{\mathrm{a}}$ & 0,2781 & 0,3575 & 0,7532 & $-0,3190$ & 0,3594 \\
$n c^{\mathrm{b}}$ & 0,5982 & 0,1967 & $-0,4888$ & 0,2140 & 0,5703 \\
$m c^{\mathrm{c}}$ & 0,7260 & $-0,0246$ & 0,0400 & $-0,0819$ & $-0,7812$ \\
$g c^{\mathrm{d}}$ & 0,1712 & $-0,6031$ & 0,4217 & 0,6371 & 0,1524 \\
greve $^{\mathrm{d}}$ & $-0,1353$ & 0,6849 & 0,1200 & 0,6632 & $-0,2417$ \\
\hline
\end{tabular}

Fuente: elaboración propia.

Nota: el número total de observaciones es de 120 ; componentes $=$ traza $=5$.

a $m g$ indica los cambios del $50 \%$ en la composición del gabinete ministerial.

b $n c$ se refiere a la interrupción del mandato constitucional del Presidente.

c $m c$ refleja los cambios de la Constitución.

d $g c$ hace referencia a las guerras civiles y actos organizados de violencia.

e greve hace referencia a las huelgas. 
GRÁFICO 1

Brasil: índice de inestabilidad política (INS), 1889-2009

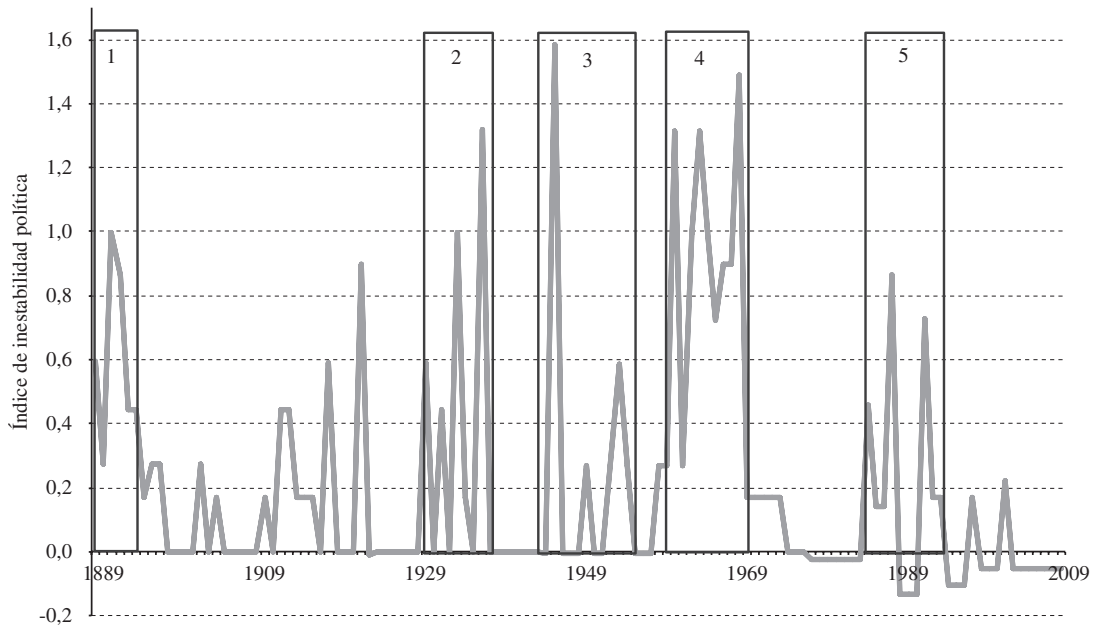

Fuente: elaboración propia (véase el anexo A.6).

Nota: se resaltan, numerados del uno al cinco, los períodos de alta inestabilidad política.

\section{Análisis de la inestabilidad política}

En el gráfico 1 se señalan cinco períodos de inestabilidad política del Brasil, que se analizan a continuación.

Período de 1889 a 1894. La Primera República fue acompañada en sus inicios de un período de alta inestabilidad política. El Presidente Mariscal Deodoro da Fonseca disolvió el Parlamento, vulnerando la Constitución que acababa de promulgarse en 1891. Esta medida fue el resultado de los desencuentros de Deodoro da Fonseca con la élite formada por los cultivadores de café. Finalmente, el Presidente renunció para evitar una guerra civil y asumió el poder el Vicepresidente Floriano Peixoto, otro militar, que tomó posesión como segundo Presidente del Brasil en 1892. Según la Constitución de 1891, debería haber convocado a elecciones nueve meses después, pero no lo hizo. Por esa razón, el Presidente Peixoto enfrentó varios levantamientos militares organizados, pero consiguió superar todas las rebeliones hasta marzo de 1894, momento en que finalizó su mandato.

Paralelamente a estos conflictos, en el sur del Brasil, en el estado de Rio Grande do Sul, se produjo la Revolución Federalista, que tuvo resultados sangrientos y finalizó en 1895. Por último, entre 1895 y 1897 estalló la Guerra de Canudos, que también produjo una significativa cantidad de víctimas mortales.

El contexto económico de ese período se caracterizó por una significativa tendencia a la baja de los precios del caucho (principal producto de exportación del país en esa época).
Después de un período de inestabilidad política, los militares renunciaron al poder y reconocieron la victoria electoral de Prudente de Morais, un cultivador de café de São Paulo, que inició el período llamado del "café con leche", durante el cual los líderes políticos de São Paulo y Minas Gerais fueron alternándose en el poder.

Todos estos fenómenos permiten caracterizar un período de alta inestabilidad política al comienzo de la Primera República. El índice elaborado registra una media de 0,601, con una desviación típica de 0,271 y un máximo de $0,997$.

Período comprendido entre 1895 y 1930. Estos años no están destacados en el gráfico 1 como períodos de extrema inestabilidad política, a pesar de la presencia de cierta intensidad de la inestabilidad relacionada con determinados factores económicos. Desde el punto de vista de dichos factores, el inicio del nuevo siglo estuvo acompañado de la recuperación de la economía internacional, que tuvo una influencia positiva en el Brasil. Según Castelar y otros (2001), la tasa de inversión en el Brasil en 1901 fue del 4,9\% del PIB y aumentó al $17,8 \%$ en 1909. Gran parte de esa inversión se destinó a la infraestructura y la industria. Entre 1901 y 1914, la red ferroviaria se incrementó un $4 \%$ y la capacidad de generación eléctrica se multiplicó por 13. Durante la Primera Guerra Mundial, las inversiones sufrieron una caída y se produjo una reducción de los términos de intercambio. Esa situación se invirtió en el período de 1918 a 1922, durante el cual las exportaciones del Brasil se duplicaron en dos años. En 1923, los ciclos de 
la economía mundial cambiaron y el Brasil enfrentó una crisis de la balanza de pagos y una alta inflación (31\% anual), lo que provocó que las políticas económicas fuesen ortodoxas durante todo el mandato del Presidente Artur Bernardes.

Al mismo tiempo, la insatisfacción de militares de graduación media se reflejó en sucesos como la Revolución del Fuerte de Copacabana en 1922 y, posteriormente, la Columna Prestes. Durante todo el gobierno del Presidente Bernardes se impuso el estado de sitio, con las consiguientes limitaciones a las libertades políticas.

La Era Vargas (1930-1945). Los cambios en el Brasil durante este período fueron una respuesta a la política del "café con leche" por parte de las élites de algunos estados (en particular, Rio Grande do Sul y Paraíba), que competían por el ejercicio del poder. La etapa conocida tradicionalmente como Era Vargas abarcó: i) el Gobierno Provisional de 1930 a 1934, como consecuencia del levantamiento cívico y militar de 1930, que dio lugar a la nueva Constitución de 1934; ii) el gobierno del Presidente Vargas entre 1934 y 1937, de cuño democrático, resultante de una elección popular; iii) el Estado Nuevo desde 1937 hasta 1945, de tipo dictatorial, durante el que se aprobó una nueva Constitución en 1937 y que terminó con un golpe de Estado en 1945, y iv) el gobierno constitucional de Getúlio Vargas, que comenzó en 1951 y finalizó con su suicidio en 1954. La Era Vargas se basó en un Estado centralizado y un Ejecutivo fuerte, lo que modificó profundamente el "pacto oligárquico" de la Primera República y constituyó una significativa fuente de conflictos. El Presidente Vargas utilizó la nueva Constitución de 1937 como mecanismo para institucionalizar ese cambio, al tiempo que clausuraba el Congreso y decretaba que los gobernadores estarían sometidos a la autoridad del Presidente.

Durante todo ese período, se produjeron acontecimientos de inestabilidad. Entre ellos se encuentran el levantamiento civil y militar de 1930, la Guerra Paulista de carácter constitucional de 1932, la instauración de la dictadura del Estado Nuevo en 1937, el derrocamiento militar de Getúlio Vargas en 1945 y su posterior suicidio en 1954.

Inestabilidad política entre 1945 y 1964. Este período se conoce como el período de la democracia populista, a causa de la sucesión de gobiernos que continuaron el legado de la Era Vargas de un desarrollo apoyado en el Estado, con un escenario internacional favorable para ese tipo de políticas. Esto permitió que el Brasil alcanzase una tasa de crecimiento del PIB per cápita cercana al 4,5\% anual, con un grado significativo de diversificación industrial. Al final del gobierno de Juscelino Kubitschek aparecieron signos de desequilibrio económico con una alta inflación. A partir de 1961, el Brasil pasó por un proceso de inestabilidad política que se acentuó en los años siguientes.

Entre 1961 y 1970. Fue el período más duradero de inestabilidad política en el Brasil, donde la Constitución brasileña se modificó cinco veces. Hubo etapas de alto crecimiento económico, pero - al mismo tiempo- se manifestaron claramente las profundas dificultades para afrontar los grandes desequilibrios económicos del Brasil. La inestabilidad política comenzó con la renuncia de Jânio Quadros en 1961 y su sustitución por el Vicepresidente João Goulart. El gobierno del Presidente Goulart adoleció de inestabilidad interna y sufrió continuos cambios en su composición ministerial. Paralelamente, se produjo una creciente movilización popular urbana y rural en la lucha por implementar reformas de la estructura del Estado brasileño en favor de las clases menos privilegiadas. Los grupos conservadores y la clase media se resistieron a los cambios y apoyaron el movimiento militar de 1964. La etapa del Gobierno Militar comenzó en 1964 con un proyecto provisional, pero posteriormente definió políticas a largo plazo a partir de 1969. Durante muchos de los gobiernos militares de ese período existió resistencia organizada en forma de movimientos guerrilleros que, a pesar de no suponer un riesgo para el poder de los militares, constituyeron un factor de inquietud política. Durante el mandato de Ernesto Geisel, los militares iniciaron un largo y costoso proceso de transición a la democracia.

Período de transición democrática (1985-1994). Este período fue complejo. La muerte del Presidente electo Tancredo Neves y la toma de posesión del Vicepresidente José Sarney hicieron que la Nueva República mostrase desde su nacimiento una gran fragilidad ante los problemas económicos heredados del último gobierno militar. Además de las dificultades económicas, el nuevo gobierno tuvo que lidiar con las reformas del Estado para democratizarlo. En 1988, se aprobó la séptima Constitución del Brasil, la más democrática de su historia, que incorporó el "ideario getulista" y protegió de la discriminación a los negros y a las mujeres. Entre 1985 y 1995, un Ministro de Hacienda tenía una gran probabilidad de permanecer en su cargo durante menos de un año tras asumir sus funciones. Como consecuencia de ello, el Brasil tuvo 11 Ministros de Hacienda ${ }^{6}$ en

\footnotetext{
${ }^{6}$ Los 11 Ministros de Hacienda fueron: Francisco Oswaldo Neves Dornelles, Dílson Domingos Funaro, Luiz Carlos Bresser Gonçalves Pereira y Maílson Ferreira de la Nóbrega (en el gobierno de José Sarney); Zeslia Maria Cardoso de Mello y Marcílio Marques Moreira (en el gobierno de Fernando Collor), y Paulo Roberto Haddad, Eliseu Resende, Fernando Henrique Cardoso, Rubens Ricupero y Ciro Ferreira Gomes (en el gobierno de Itamar Franco).
} 
10 años. La inestabilidad política en 1992 se debió al derrocamiento constitucional del Presidente Fernando Collor a través de un juicio político.

Entre 1995 y 2009, el Brasil experimentó su más largo período de estabilidad política en la historia moderna del país, en gran parte gracias al equilibrio macroeconómico alcanzado por el gobierno del Presidente Fernando Henrique Cardoso y consolidado durante el mandato del Presidente Luís Inácio da Silva.

En el cuadro 3 se incluye un resumen de los resultados obtenidos con el INs, en el que se señalan los períodos de mayor inestabilidad (1889-1894, 1895-1930, 1931-1945,

CUADRO 3

Brasil: valores del índice de inestabilidad política (INS) en los principales episodios de inestabilidad, 1889-1994

\begin{tabular}{|c|c|c|}
\hline Período & $\begin{array}{l}\text { Media/desviación } \\
\text { típica del INS }\end{array}$ & Episodios de inestabilidad \\
\hline $1889-1894$ & $0,600 / 0,278$ & $\begin{array}{l}\text { - Deodoro da Fonseca disolvió el Parlamento } \\
\text { - Floriano Peixoto asumió el poder y no convoca a nuevas elecciones } \\
\text { - Levantamientos militares constitucionales contra Floriano Peixoto }\end{array}$ \\
\hline $1895-1930$ & $0,132 / 0,217$ & $\begin{array}{l}\text { - Guerra Federalista en Rio Grande do Sul } \\
\text { - Guerra de Canudos } \\
\text { - Revolución del Fuerte de Copacabana } \\
\text { - Columna Prestes }\end{array}$ \\
\hline $1931-1945$ & $0,194 / 0,413$ & $\begin{array}{l}\text { - Golpe civil y militar liderado por Getúlio Vargas } \\
\text { - Constituciones de } 1934 \text { y } 1937 \\
\text { - Declaración del Estado Nuevo con disolución del Congreso } \\
\text { - Guerra Paulista de } 1932 \\
\text { - Golpe militar contra Getúlio Vargas en } 1945\end{array}$ \\
\hline $1961-1970$ & $0,906 / 0,430$ & $\begin{array}{l}\text { - Renuncia de Jânio Quadros } \\
\text { - João Goulart asumió el poder } \\
\text { - Cambios frecuentes de más del 50\% de la composición del gabinete } \\
\text { - Manifestaciones públicas en favor y en contra de las reformas del Estado } \\
\text { - Golpe de Estado de } 1964 \\
\text { - Podificación de la Constitución (cinco veces) } \\
\text { - Promulgación del Acto Institucional Número Cinco } \\
\text { Pria de movimientos armados insurgentes }\end{array}$ \\
\hline 1985-1994 & $0,359 / 0,536$ & $\begin{array}{l}\text { - Muerte del Presidente electo Tancredo Neves } \\
\text { - Juicio político constitucional del Presidente Fernando Collor } \\
\text { - Continuos cambios del Ministro de Hacienda } \\
\text { - Seis planes de estabilización económica fracasados }\end{array}$ \\
\hline
\end{tabular}

Fuente: elaboración propia.

1961-1970 y 1985-1994) y los respectivos valores medios y desviaciones típicas del INS. Se puede observar que la mayor inestabilidad corresponde al período comprendido entre los años 1961 y 1970, seguido por el lapso de 1889 a 1894 y por el proceso de transición democrática. Esto demuestra que, con excepción de la Primera República, la inestabilidad política es un fenómeno característico del Brasil moderno.

\section{Correlación estadística entre el INS y una selección de variables económicas}

En esta subsección se presentan los indicadores de correlación estadística entre el INS y determinadas variables económicas. El propósito es descriptivo y se orienta a evaluar si el indicador se relaciona con otras variables en la dirección lógica que podría esperarse. Además, se realizan calificaciones de tipo general de la intensidad de las correlaciones calculadas.

Los indicadores económicos escogidos fueron el nivel del PIB, las inversiones, los términos de intercambio, la inflación, las crisis internacionales, el déficit fiscal y la población. Como el indicador producido abarca una larga serie temporal, correspondiente al período 18892009, se utilizaron diversas fuentes de información, con series de un gran número de años.

Para la serie del producto se empleó el estudio de Maddison (2008), que contiene datos del PIB del Brasil de 1870 a 2007. También se utilizaron los datos del PIB del Instituto Brasileño de Geografía y Estadística (IBGE)- 
Histórico, que contiene datos del PIB entre 1900 y 2007. Además de esa información, el IBGE-Histórico proporciona datos sobre inversiones y términos de intercambio de esos períodos. Otra fuente de información fue el estudio de Heston, Summers y Aten (2008), que incluye datos sobre el producto y las inversiones de 1950 a 2007, los que se indican en el cuadro 4 como Penn World Tables $(P W T)$. Para los datos de inflación y crisis internacionales se utilizó la información de Rogoff y Reinhart (2011) sobre el Brasil a partir de 1830. En cuanto a los datos de déficit fiscal, se usó la serie de 1900 a 2007 que se encuentra disponible en el sitio web de Ipeadata. Las fuentes de esos datos corresponden al Ministerio de Hacienda. Por medio del indicador del déficit fiscal, se calculó el porcentaje que representa el déficit con respecto al PIB estimado por el IBGE-Histórico.

Disponer de diferentes fuentes para una misma variable, como sucedió en el caso del producto, permitió comparar las diferentes estimaciones a fin de obtener conclusiones más robustas.

En el cuadro 4, que se incluye a continuación, se observan los coeficientes de correlación y se destacan las diferentes fuentes de información. Como los datos de Heston, Summers y Aten (2008) tienen al año 1950 como año inicial, se decidió presentar los coeficientes de correlación de las otras fuentes, en particular las de Maddison (2008), IBGE-Histórico y Rogoff y Reinhart (2011) en períodos comparables.

El análisis del cuadro 4 se realizó en orden descendente de los indicadores escogidos. Se descubrió una relación negativa entre inestabilidad política y producto. En el caso de los períodos más largos, esa correlación no parece muy significativa. Sin embargo, cuando se considera el período a partir de 1950, la correlación es significativa y las tres fuentes de información muestran resultados similares. La diferencia de la correlación entre los dos períodos indica que, en los años de modernización del Brasil, la inestabilidad política tuvo efectos más acentuados en la reducción del producto. Un análisis más detallado y en profundidad de ese fenómeno excedería los objetivos de este artículo. Cabe destacar que el fenómeno indicado se refleja en las tres fuentes de información.

También se observa una correlación negativa entre la inversión y la inestabilidad política, que es casi nula en la serie del IBGE-Histórico considerando casi todo el período, pero esa situación cambia cuando se considera únicamente el período más reciente entre 1950 y 2009. Un antecedente de interés que debe tenerse en cuenta es el comportamiento de las inversiones en el Brasil en dos subperíodos. De 1900 a 1950, el nivel medio de inversión fue del 10,5\% del PIB, con un valor máximo del 20,3\% del PIB y un valor mínimo de un 4,21\% del PIB. Entre 1950 y 2007, el nivel medio de inversión fue del $18,4 \%$, con valores extremos que fluctuaron entre el $12,8 \%$ y el 26,9\% del PIB. En los períodos más recientes, la inversión constituyó una mayor proporción de la demanda agregada y, por lo tanto, su comportamiento debía acompañar más estrechamente las variaciones del producto y de los choques internos y externos de la economía brasileña. Esa situación posiblemente explique la mayor correlación entre inversión e inestabilidad política en períodos más recientes.

Resulta interesante evaluar la correlación entre los términos de intercambio internacionales y la inestabilidad política, ya que uno de los canales por los que se realiza la transmisión de la inestabilidad política es a través de los choques negativos en los mercados internacionales de los productos de exportación del Brasil. Para realizar esa evaluación, se utiliza un indicador de las variaciones de los términos de intercambio de un año en relación con el año anterior. Además, se considera la volatilidad de los términos de intercambio ${ }^{7}$ que, para un año determinado, es igual a la desviación típica del índice de las relaciones de intercambio internacionales en los cinco años anteriores, dividido por el promedio de los términos de intercambio en los cinco años precedentes. Por lo tanto, la volatilidad de los términos de intercambio en un año refleja la variabilidad de las relaciones internacionales de intercambio en los cinco años anteriores. Por eso, la serie de volatilidad tiene a 1905 como su primer año. La definición y los datos de volatilidad se obtuvieron de la base del IBGE-Histórico. Otro dato que se considera como indicador sustitutivo de la situación de la economía internacional del Brasil es el nivel de actividad económica de los países más relevantes, que es el promedio del PIB per cápita de los Estados Unidos de América, Alemania, el Reino Unido de Gran Bretaña e Irlanda del Norte y el Japón. Para obtener este último indicador se utilizó la base de datos de Maddison (2008). Todos los indicadores apuntan en la misma dirección. La variación de las relaciones de intercambio internacionales tiene una débil correlación con el INS. En cambio, la volatilidad de los términos de intercambio tiene un efecto más significativo y, sin duda, el nivel de actividad económica de los países más relevantes muestra una clara correlación con la inestabilidad política.

\footnotetext{
7 En este artículo, "términos de intercambio" y "relaciones de intercambio internacionales” son sinónimos.
} 
CUADRO 4

Brasil: coeficientes de correlación entre el INS y una selección de variables económicas, 1889-2007

\begin{tabular}{|c|c|c|c|}
\hline Fuentes/variables & Años & Número de años & Coeficiente de correlación \\
\hline \multicolumn{4}{|c|}{ Producto interno bruto } \\
\hline Maddison & $1889-2007$ & 118 & $-0,1771 * *$ \\
\hline Instituto Brasileño de Geografía y Estadística (IBGE)-Histórico & $1901-2007$ & 106 & $-0,1431 * * *$ \\
\hline Penn World Tables (PWT) & $1950-2007$ & 57 & $-0,4475^{*}$ \\
\hline Maddison & $1950-2007$ & 57 & $-0,4698 *$ \\
\hline IBGE & $1950-2007$ & 57 & $-0,4611^{*}$ \\
\hline \multicolumn{4}{|c|}{ Inversión } \\
\hline IBGE-Histórico & $1901-2007$ & 106 & $-0,0154$ \\
\hline IBGE-Histórico & $1950-2007$ & 57 & $-0,2447$ \\
\hline$P W T$ & $1950-2007$ & 57 & $-0,1315$ \\
\hline \multicolumn{4}{|c|}{ Términos de intercambio } \\
\hline Variación de los términos de intercambio & $1905-2007$ & 102 & $-0,0403$ \\
\hline Volatilidad de los términos de intercambio & $1905-2007$ & 102 & $-0,1848 * * *$ \\
\hline Producto mundial & $1889-2007$ & 118 & $-0,147 * * *$ \\
\hline Producto mundial & $1950-2007$ & 57 & $-0,4124 *$ \\
\hline \multicolumn{4}{|c|}{ Inflación } \\
\hline Variación de los precios & $1889-2007$ & 118 & $-0,045$ \\
\hline Variación de los precios & $1950-2007$ & 57 & $-0,073$ \\
\hline \multicolumn{4}{|c|}{ Crisis financieras } \\
\hline Crisis financieras & $1889-2007$ & 118 & $0,1371 * * *$ \\
\hline Crisis financieras & 1950-2007 & 57 & $0,2109 * * *$ \\
\hline \multicolumn{4}{|c|}{ Déficit fiscal } \\
\hline Déficit fiscal federal & $1900-2007$ & 107 & $-0,0807 * *$ \\
\hline Déficit fiscal federal & $1950-2007$ & 57 & $-0,0691$ \\
\hline Ingresos del gobierno & $1900-2007$ & 107 & $-0,2271 *$ \\
\hline Ingresos del gobierno & $1950-2007$ & 57 & $-0,3717^{*}$ \\
\hline Gastos del gobierno & $1900-2007$ & 107 & $-0,2082^{*}$ \\
\hline Población & $1889-2007$ & 118 & $-0,148 * * *$ \\
\hline & $1950-2007$ & 57 & $-0,412^{*}$ \\
\hline
\end{tabular}

Fuente: elaboración propia sobre la base de A. Maddison (2008), The World Economy: Historical Statistics, París, Centro de Desarrollo de la OCDE, 2008 [en línea] http://www.ggdc.net/maddison/; A. Heston, R. Summers y B. Aten, "Penn World Tables Version 6.1", Center for International Comparisons at the University of Pennsylvania, 2008 [en línea] http://pwt.econ.upenn.edu/; y K. Rogoff y C. Reinhart, "From financial crash", American Economic Review, vol. 101, № 5, Nashville, Tennessee, American Economic Association, 2011.

INS: índice de inestabilidad política.

* Significación estadística del 1\%; ** significación estadística del 5\%; *** significación estadística del 10\%.

La correlación entre el INS y la inflación tiene el sentido esperado, pero es de escasa magnitud y no resulta estadísticamente significativa. La economía brasileña ha tenido una trayectoria bastante larga de convivencia con la inflación y, por lo tanto, resultaría bastante aventurado afirmar que la economía del Brasil mostraba inestabilidad política en los años en que existía una inflación más alta. Más adecuado sería decir que se produjo una crisis política causada por la inflación en los años en que existieron episodios hiperinflacionarios, es decir, en el período 1988-1994 en el caso brasileño.
El indicador de las crisis financieras elaborado por Rogoff y Reinhart (2011) se refiere a cuatro tipos de crisis financieras: crisis del tipo de cambio y alta inflación, cesación de pago de las deudas externas e internas del gobierno, hundimientos de los mercados de capitales y crisis bancarias. Cada una de estas crisis se evalúa como una variable categórica, con valor 1 cuando el fenómeno está presente ese año y con valor 0 en caso contrario. Finalmente, los autores establecen una variable de síntesis, sumando los diferentes tipos de crisis definidos. En el cuadro 4 se utiliza esa variable de 
síntesis que resume los cuatro tipos de crisis financieras. En principio, debería existir una correlación positiva entre el indicador de crisis financiera y el índice INS, cuyos resultados se presentan en el cuadro 4 . Al igual que sucede con otros indicadores empleados en el cuadro 4 , los efectos de las crisis financieras muestran una correlación más intensa con la inestabilidad política a partir de 1950. El promedio de las crisis financieras entre 1889 y 2007 es de 1,44. Lo más significativo de la serie de Rogoff y Reinhart (2011) es que el promedio de esa serie fue de 0,95 en el período de 1889 a 1950 y de 1,96 durante el siguiente período. Eso significa que la profundidad de las crisis financieras en el Brasil fue mucho mayor en los años más recientes. El valor máximo del indicador de la crisis financiera fue de 6 en el año 1986, según el índice de crisis financieras estimado por Rogoff y Reinhart (2011). Ese año, todos los tipos de crisis definidos por los autores estuvieron presentes en el Brasil. Resulta muy significativo que, desde la crisis de la deuda externa en México en 1982 hasta el inicio del Plan Real en el Brasil en 1994, el índice de crisis financiera fuera de 3,9, el nivel más alto de la historia financiera del Brasil en más de un siglo.

Otro indicador utilizado fue la correlación entre el INS y el déficit fiscal como porcentaje del PIB. Si existía un déficit, el indicador del déficit fiscal era negativo. Teniendo en cuenta que cuanto mayor es la inestabilidad política mayor es el índice estimado, debería existir una relación negativa entre ambos indicadores. En efecto, en el cuadro 4 se puede observar que existe una correlación negativa entre déficit fiscal e inestabilidad política. Esta correlación disminuyó moderadamente entre 1950 y 2007. La variación entre los dos períodos se debe a que el Brasil mostró sistemáticamente déficits fiscales desde 1900 hasta 1950. Solo se consiguió el equilibrio fiscal en 9 de esos años, mientras que en los otros 41 años se registraron déficits. Entre 1950 y 2009 sucedió lo contrario: solo 20 años mostraron déficits y, en especial desde 1976, únicamente hubo déficit en 3 años. Esto fue el resultado de las políticas de combate a la inflación aplicadas en esos años, que se basaron en el equilibrio fiscal. Las correlaciones entre gastos públicos e ingresos del gobierno, por una parte, y la inestabilidad política, por otra, son más claras.

Finalmente, se considera la correlación entre la población y el INS. La idea de este cálculo es analizar si el crecimiento del país en cuanto a la población, con todos los fenómenos que eso implica, tiene una relación con la inestabilidad política. El resultado es que, en efecto, existe una correlación negativa entre la población y el INS.

Del cálculo de los indicadores de correlación presentados, se pueden sacar las siguientes conclusiones: i) existe una correlación entre el índice estimado y las variables económicas escogidas, en el sentido esperado; ii) esos resultados son robustos, ya que los indicadores elaborados con datos de diferentes fuentes dan lugar a resultados similares; iii) se observa que la intensidad de esa correlación es mayor a partir del año 1950, que fue el período en que el país comenzó un proceso de modernización y adquirió una mayor complejidad productiva.

\section{VI}

\section{Consideraciones finales}

Con respecto a las diversas investigaciones, es importante tener en cuenta las interacciones que existen entre variables sociales, económicas y políticas. Al intentar entender la trayectoria política y económica de un país, esta visión caleidoscópica puede ser especialmente necesaria para lograr explicar las causas de los éxitos (y de los fracasos) de su proceso de desarrollo.

Dado que en muchos estudios referentes a la economía brasileña no se tiene en cuenta esta compleja interacción histórica, sobre todo porque no existe una variable que contemple todas estas dimensiones de forma consistente, el presente estudio tiene como propósito construir un INs para el Brasil para el período comprendido entre 1889 y 2009, basado en la técnica estadística de componente principal (CP).

Se considera que el índice elaborado captura los principales ciclos de inestabilidad política en la historia del Brasil. Por otra parte, el análisis de la serie permite establecer que esos ciclos corresponden solo a determinados años y que, por lo tanto, se trata de un país con una baja inestabilidad política.

De este modo, esta investigación ha contribuido a la bibliografía relacionada con la elaboración de un INs para el Brasil, anteriormente inexistente, que podrá utilizarse en diversos estudios con el propósito de llenar un vacío existente desde el punto de vista histórico y empírico. 
ANEXOS

\section{Fuentes de información de las variables}

A.1 Variable: interrupción del mandato constitucional $(n c)$

Para cuantificar esta variable, se utilizaron los siguientes criterios y fuentes de información:

i) Características del período del mandato constitucional para el Presidente y normas sobre su sustitución, que se detallan en el anexo A.3.

ii) Diferentes actos que muestran la interrupción del mandato constitucional del Presidente $(n c)$.

- 1889: golpe de Estado de Deodoro da Fonseca contra el Emperador Pedro II.

- 1892: golpe de Estado de Floriano Peixoto contra Deodoro da Fonseca.

- 1918: muerte del Presidente electo Rodríguez Alves, que no llegó a tomar posesión.

- 1930: levantamiento civil y militar de Getúlio Vargas.

- 1937: Getúlio Vargas se declara dictador.

- 1946: Getúlio Vargas es depuesto.

- 1954: suicidio de Getúlio Vargas.

- 1961: renuncia de Jânio Quadros.

- 1964: golpe militar.

- 1969: muerte de Costa Silva y sustitución inconstitucional por una junta militar.

- 1985: muerte del Presidente electo Tancredo Neves.

- 1992: deposición constitucional del Presidente Fernando Collor de Mello.

\section{A.2 Cambio del $50 \%$ de la composición del gabinete $(m g)$}

Para generar estadísticas de calidad con esta variable, se requiere conocer el número de ministerios en todos los períodos estudiados y el nombre de los ministros, además de cuantificar, respecto de cada año, el número de veces que esos cambios superaron la mitad del número de ministros.

Con el objeto de establecer el número de ministerios, se elaboró una lista ordenada por fecha de su fundación, que indicaba los cambios de nombre y el año de extinción. Esta información se recoge en el cuadro A.2.

Utilizando estos datos, se elaboró una lista del número de ministerios correspondiente a cada Presidente del Brasil desde 1889 hasta 2009, es decir, las 34 personas que tomaron oficialmente posesión del cargo de Presidente de la República. En esa relación, no se consideraron las juntas gubernamentales de 1930 y 1969 , ni los tres presidentes que no llegaron a tomar posesión (Júlio Prestes, Rodríguez Alves y Tancredo Neves), el primero a causa del levantamiento militar de $1930 \mathrm{y}$ los otros dos debido a sus respectivos fallecimientos.

No se tuvieron en cuenta los cambios en los gabinetes de ministros de los siguientes gobiernos provisionales:

- Junta gubernamental (1930), del 24 de octubre de 1930 al 3 de noviembre de 1930.

- José Linhares (1945), del 29 de octubre de 1945 al 31 de enero de 1946.

- Carlos Luz (1955), del 8 de noviembre de 1955 al 11 de noviembre de 1955.

- $\quad$ Nereu Ramos (1955), del 11 de noviembre de 1955 al 31 de enero de 1956.

- Gobiernos provisionales de Ranieri Mazzilli de 1961 (25 de agosto de 1961) y 1964 ( 2 de abril de 1964 al 15 de mayo de 1964).

- Junta gubernamental provisional (1969), del 31 de agosto de 1961 al 30 de octubre de 1969.

Con respecto a cada gobierno se determinó el nombre de los ministros y la fecha de inicio y fin de sus funciones, así como el número de ministros desde la fundación de la República. Por ejemplo, Rui Barbosa fue el primer Ministro de Hacienda del Brasil, en el gobierno de Deodoro da Fonseca y, por lo tanto, se le asignó el $\mathrm{N}^{\circ} 1$, mientras que Guido Mantega es el Ministro de Hacienda $\mathrm{N}^{\mathrm{o}} 71$ y pertenece al gobierno del Presidente Luís Inácio Lula da Silva. Este registro permitió controlar exactamente todos los ministros y ministerios existentes durante cada mandato presidencial. De la lista de ministerios, se excluyó el Ministerio de la Desburocratización, de corta duración, creado el 18 de julio de 1979 y suprimido el 14 de febrero de 1986. Tampoco se incluyó al Ministerio de Reforma Administrativa, creado durante el mandato del Presidente Fernando Collor de Mello, que fue eliminado por el Presidente Itamar Franco.

Si la cantidad de cambios de ministro en un año era mayor que la mitad del número total de ministerios, se deducía que en ese año había existido una situación de inestabilidad política. Para los efectos del estudio, no se consideró como un cambio de ministros la sustitución por un ministro interino. Si en un determinado ministerio se habían producido dos o más cambios en un año, esos cambios se contabilizaban como tales. En los casos del Presidente Fernando Henrique Cardoso y del Presidente Luís Inácio Lula da Silva, que tuvieron un segundo mandato, se consideraron los cambios de cada mandato de manera independiente. Es decir, en el año en que el Presidente tomaba posesión para un nuevo mandato, el 


\begin{tabular}{|c|c|c|}
\hline & Ministerio & Año de creación \\
\hline 1 & Ministerio de Hacienda (MF) & 1808 \\
\hline 2 & Ministerio de Justicia (MJ) & 1822 \\
\hline 3 & Ministerio de Relaciones Exteriores (MRE) & 1852 \\
\hline 4 & Ministerio de Agricultura, Ganadería y Abastecimiento (MA) & 1909 \\
\hline 5 & Ministerio de Transporte ${ }^{\mathrm{a}}(\mathrm{MT})$ & 1861 \\
\hline 6 & Ministerio de la Marina ${ }^{\mathrm{b}}$ (MM) & 1891 \\
\hline 7 & Ministerio del Ejército $^{\mathrm{b}}(\mathrm{ME})$ & 1891 \\
\hline 8 & Ministerio de Trabajo y Empleo (MTE) & 1930 \\
\hline 9 & Ministerio de Aeronáutica ${ }^{b}$ (MAER) & 1941 \\
\hline 10 & Ministerio de Salud (MSAU) & 1953 \\
\hline 11 & Ministerio de Desarrollo, Industria y Comercio Exterior ${ }^{\mathrm{c}}$ (MD) & 1960 \\
\hline 12 & Ministerio de Minas y Energía (MME) & 1960 \\
\hline 13 & Ministerio de Planificación (MPL) & 1962 \\
\hline 14 & Ministerio de Comunicaciones (MC) & 1967 \\
\hline 15 & Ministerio de Medio Ambiente (MMA) & 1973 \\
\hline 16 & Ministerio de Previsión Social (MPS) & 1974 \\
\hline 17 & Ministerio de Cultura (MCUL) & 1985 \\
\hline 18 & Ministerio de Ciencia, Tecnología e Innovación (МтCT) & 1985 \\
\hline 19 & Ministerio de Turismo (MTUR) & 1992 \\
\hline 20 & Ministerio de Deporte (MES) & 1995 \\
\hline 21 & Ministerio de Integración Nacional (MINT) & 1999 \\
\hline 22 & Ministerio de Desarrollo Agrario (MDA) & 1999 \\
\hline 23 & Ministerio de Defensa (MD) & 1999 \\
\hline 24 & Ministerio de las Ciudades (MCIDADES) & 2003 \\
\hline 25 & Ministerio de Pesca y Acuicultura (MPESC) & 2003 \\
\hline 26 & Ministerio de Desarrollo Social y Lucha contra el Hambre (MFOME) & 2004 \\
\hline
\end{tabular}

Fuente: elaboración propia.

a Este ministerio tuvo diversas denominaciones. 1860-1891: Secretaría de Estado de Negocios de la Agricultura, Comercio y Obras Públicas; 1891-1906: Ministerio de Industria, Tráfico y Obras Públicas; 1906-1967: Ministerio de Tráfico y Obras Públicas; 1967-1990: Ministerio de Transporte; 1990-1992: Ministerio de Infraestructura; 1992-1992: Ministerio de Transporte y Comunicaciones, y 1992-2012: Ministerio de Transporte.

b Extintos en virtud de la Ley complementaria No 97 de 10 de junio de 1999, que creó el Ministerio de Defensa.

c Ministerio extinto entre 1990 y 1992.

cambio de un ministro entre el fin del primer mandato y el inicio del segundo no se consideró como un cambio de ministro para los efectos del estudio.

Finalmente, no se tuvieron en cuenta los cambios de secretarías u otras instituciones que tuvieran la condición de ministerios. La única excepción a esa regla correspondió al Ministerio de la Casa Civil, que se creó el 3 de noviembre de 1930 como Secretaría de la Presidencia de la República y se convirtió en Casa Civil el 1 de diciembre de 1938. Esa decisión se debió a que el Ministro de la Casa Civil es una institución de gran relevancia política en el Brasil y tiene funciones similares a las del Primer Ministro en un régimen parlamentario ${ }^{8}$.

${ }^{8}$ El resultado de este levantamiento se encuentra en un anexo de 70 páginas que, por limitaciones de espacio, no forma parte de este artículo, pero que está disponible para quien lo solicite.

\section{A.3 Cambios de la Constitución (mc)}

El análisis de este punto es relevante para calificar si se ha interrumpido el mandato del Presidente de acuerdo con la Constitución. El Brasil ha tenido siete Constituciones: 1822, 1891, 1934, 1937, 1946, 1967 y 1988. Las reformas constitucionales han sido ocho: 1927, 1961, 1963, 1964-1967, 1967, 1968, 1969 y 1979. Los puntos por destacar en cada Constitución o enmienda constitucional fueron los siguientes:

- El mandato presidencial según la Constitución, en número de años.

- Los procesos de sustitución del Presidente en caso de que el presidente electo no pudiera ejercer el mandato constitucional por fallecimiento o remoción constitucional.

- Las normas mediante las que los regímenes de excepción, surgidos por el ejercicio de la fuerza, 
regularon su sistema de sucesión presidencial. En particular, fue el caso de los gobiernos militares de 1964 a 1985.

Con respecto a los temas señalados, la situación dependía de cada Constitución:

- Constitución de 1891: el mandato del Presidente de la República duraba cuatro años. El Presidente electo no podía ser candidato a un nuevo mandato. En caso de muerte o renuncia del Presidente, el Vicepresidente asumía el poder solo hasta que se realizara una nueva votación, en lugar de hasta completar el mandato, como ocurre actualmente (Constituciones brasileñas de 1891 y 1957).

- Constitución de 1934: el mandato del Presidente era de cuatro años y la sustitución duraba el tiempo suficiente para organizar unas nuevas elecciones (Arruda y Caldeira, 1986).

- Constitución de 1937: el mandato era de seis años, con posibilidad de reelección (Arruda y Caldeira, 1986).

- Constitución de 1946: el mandato presidencial era de cinco años (Montellato, Cabrini y Catelli Jr., 2000).

- Constitución de 1966: el mandato presidencial era de cinco años (Montellato, Cabrini y Catelli Jr., 2000).

- Enmienda constitucional de 1961: cambió el sistema de presidencial a parlamentario.

- Enmienda constitucional de 1963: cambió el sistema de parlamentario a presidencial.

- $\quad$ Enmienda constitucional de 1969: creación de la junta militar que sustituyó al Presidente Costa Silva.

- $\quad$ Acto Institucional Número Uno: realizó una purga de políticos y ciudadanos opositores; rigió las elecciones entre 1964 y 1967.

- Acto Institucional Número Dos: disolvió los partidos existentes y estableció, en la práctica, el bipartidismo entre 1964 y 1967.

- Acto Institucional Número Tres: instituyó la celebración de elecciones directas para los gobiernos de los estados. Los prefectos de capitales y "municipios de área de seguridad nacional" pasaron a ser nombrados por los gobernadores en 1964.

- Acto Institucional Número Cuatro: compelió al Congreso a votar el proyecto de Constitución de 1967.

- Acto Institucional Número Cinco: disolvió el Congreso, suspendió las garantías constitucionales y otorgó poderes al Ejecutivo para legislar sobre todos los asuntos en 1969.
- Enmienda constitucional: revocación del Acto Institucional Número Cinco en 1979.

- Constitución de 1988: mandato presidencial de cuatro años; en caso de fallecimiento del Presidente, el Vicepresidente asumía el poder hasta el fin del mandato.

Fuente: http://www.duplipensar.net/dossies/historia-de las-eleicoes.

\section{A.4 Guerras civiles y actos de violencia política organizada y registrada en la historia del Brasil (gc)}

Las guerras civiles o actos de violencia organizada registrados en la historia brasileña son los siguientes:

- Guerra de Canudos entre 1896 y 1897.

- Revolución Federalista entre 1893 y 1895.

- Revuelta de la Vacuna de 1904.

- Revuelta del Látigo de 1910.

- Guerra del Contestado entre 1912 y 1916.

- Revolución del Fuerte de Copacabana de 1922.

- Revolución Paulista de 1922.

- Revolución Constitucionalista de 1932.

- Intentona Comunista de 1935.

- Guerrilla de Caparão de 1967.

- Guerrilla de Araguaia entre 1967 y 1974.

Fuente: J. Schulz, O Exército na política: origens da intervenção militar, 1850-1894, São Paulo, Editora da Universidade de São Paulo (EDUSP), 1994; y E. Seidl, "A formação de um exército à brasileira: lutas corporativas e adaptação institucional", História, vol. $29, \mathrm{~N}^{\circ} 2$, São Paulo, 2010.

Entre los sucesos indicados anteriormente, se excluyeron:

i) La Revuelta de la Vacuna, ya que no tuvo un objetivo político definido. Fue una resistencia popular contra los métodos de aplicación y generalización de las vacunas en la ciudad de Río de Janeiro. Esa iniciativa incluía la destrucción de viviendas y barrios marginales, lo que provocó un clima de resistencia popular.

ii) La Revuelta del Látigo, por el hecho de que se trató de actos de indisciplina dentro de la Marina brasileña, en respuesta a brutalidades impuestas por la jerarquía de esa institución. 


\section{A.5 Huelgas (greve)}

Las estadísticas de las huelgas se basaron en Noronha (2009) para los años comprendidos entre 1978 y 2007, mientras que para los años anteriores se recurrió a Simão (1981).

Para evaluar el efecto de las huelgas, se normalizó esta variable en el intervalo [0,1] a través del valor de todos los años en relación con el valor máximo que corresponde al período 1990-1992.
CUADRO A.5

Brasil: número de huelgas, 1888-2002

\begin{tabular}{lc}
\hline Período & Número de huelgas al año \\
\hline $1888-1890$ & 2 \\
$1901-1914$ & 9 \\
$1914-1929$ & 8 \\
$1930-1936$ & 12 \\
$1937-1944$ & 1 \\
$1945-1964$ & 43 \\
$1965-1968$ & 13 \\
$1969-1977$ & 0 \\
$1978-1984$ & 214 \\
$1985-1989$ & 102 \\
$1990-1992$ & 1126 \\
$1993-1994$ & 842 \\
$1995-1998$ & 865 \\
$1999-2002$ & 440
\end{tabular}

Fuente: E.G. Noronha, "Ciclo de greves, transição política e estabilização: Brasil, 1978-2007”, Lua Nova, N 76, São Paulo, 2009; A. Simão, Sindicato e Estado. Suas relações na formação do proletariado de São Paulo, São Paulo, Editora Ática, 1981. 


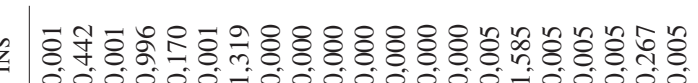

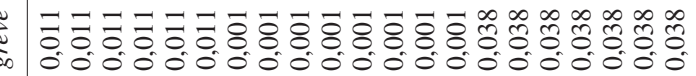

$\because 0-00-0000000000000000$

$000-00-00000000-00000$

$000000-00000000-00000$

$0-0-00000000000-000-0$

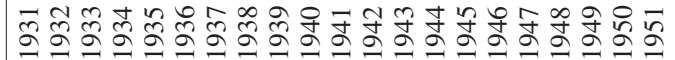

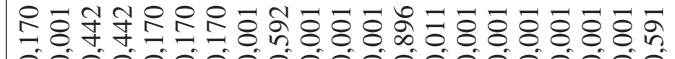
1

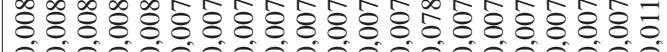

$-0-1-100000-00000000$

$000000000000-00000000$

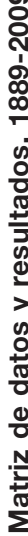

$00000000-00000000000-$

$\cong 00--00000000000000000$

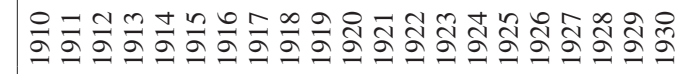

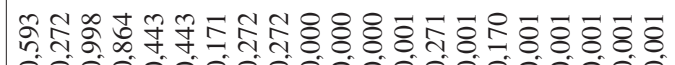

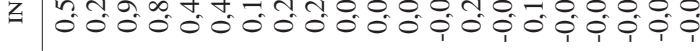

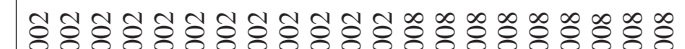

00000000000000000

$0000-7-00000000-00000$

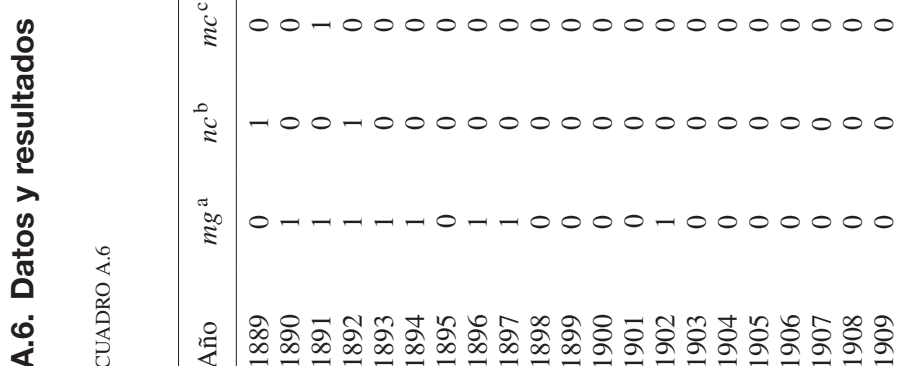




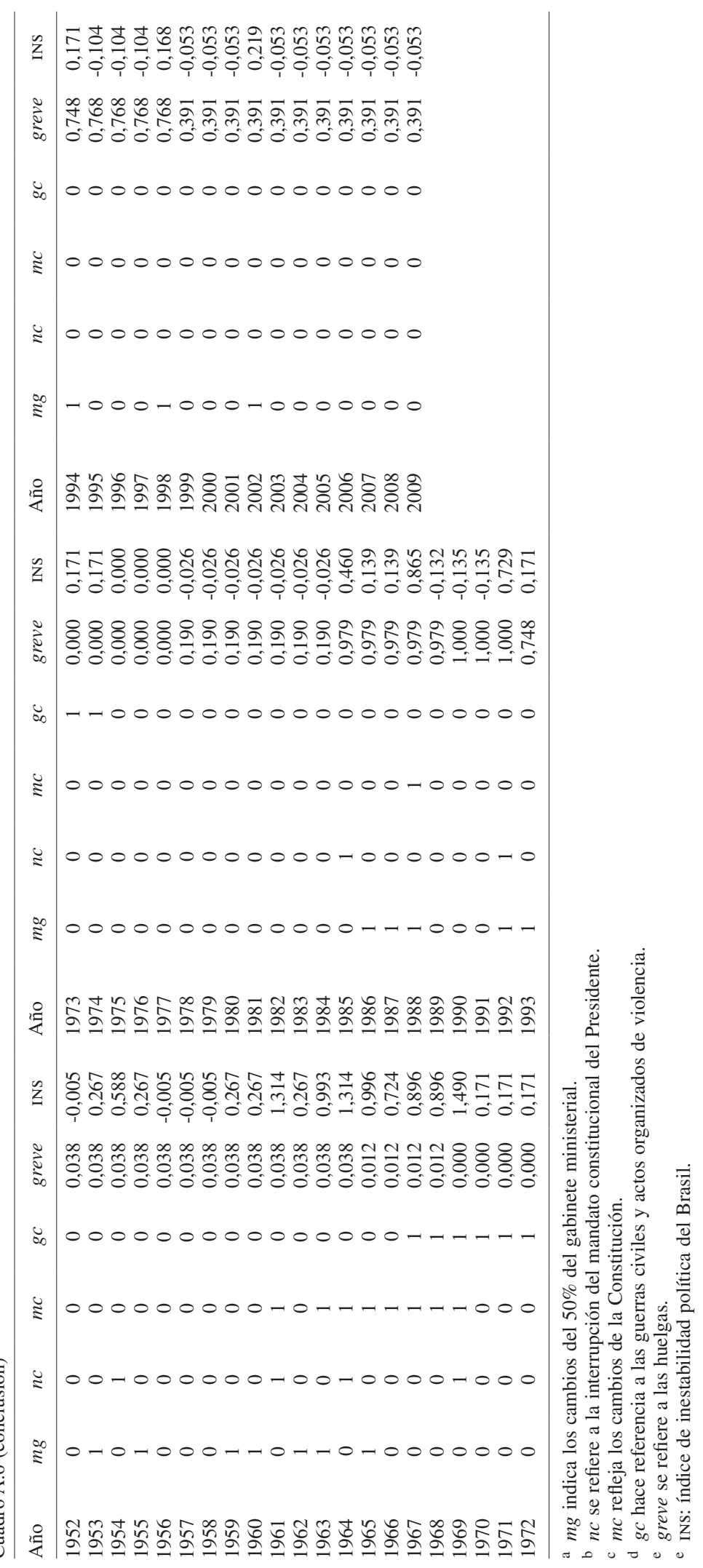




\section{Bibliografía}

Abreu, M. de Paiva (2000), "The Brazilian economy, 1928-1980", Texto para Discussão, № 433, Río de Janeiro, Departamento de Economía, Pontificia Universidad Católica de Río de Janeiro. (1999), O Brasil e a economia mundial, 1930-1945, Río de Janeiro, Civilização Brasileira.

Aisen, A. y F. Veiga (2011), "How does political instability affect economic growth?", IMF Working Papers, $\mathrm{N}^{\circ} 11 / 12$, Washington, D.C., Fondo Monetario Internacional.

Alesina, A. y G. Tabellini (1990), "A positive theory of fiscal deficits and debt", Review of Economic Studies, vol. 57, № 3, Oxford, Oxford University Press.

Alesina, A. y otros (1992), "Political instability and economic growth", NBER Working Papers, $\mathrm{N}^{\circ} 4173$, Cambridge, Massachusetts, National Bureau of Economic Research (NBER).

Annett, A. (2001), "Social fractionalization, political instability, and the size of government", IMF Staff Papers, vol. 48, $\mathrm{N}^{\circ} 3$, Washington, D.C., Fondo Monetario Internacional.

Arruda, M. y C. Caldeira (1986), Como surgiram as constituições brasileiras, Río de Janeiro, Federación de Organos para Asistencia Social y Educacional (FASE).

Barro, R. (1996), "Determinants of economic growth: a cross-country empirical study", NBER Working Paper, $\mathrm{N}^{\circ}$ 5698, Cambridge, Massachusetts, National Bureau of Economic Research. (1991), "Economic growth in a cross section of countries", Quarterly Journal of Economics, vol. 106, ํㅜ 2, Oxford, Oxford University Press.

Bohn, F. (2003), "A note on corruption and public investment: the political instability threshold", Economics Discussion Papers, $\mathrm{N}^{\circ}$ 559, Universidad de Essex.

Castelar, A. y otros (2001), "Brazilian Economic Growth, 1900-2000: Lessons and Policy Implications", Río de Janeiro, borrador.

Constituição Brasileira de 1896 (1957), Planalto Central do Brasil, Coleção Documentos Brasileiros, Livraria José Olympio Editora.

Cukierman, A., S. Edwards y G. Tabellini (1992), "Seigniorage and political instability", American Economic Review, vol. 82, $\mathrm{N}^{\circ}$ 3, Nashville, Tennessee, American Economic Association.

Devereux, M.B. y J.F. Wen (1998), "Political instability, capital taxation and growth", European Economic Review, vol. 42, $\mathrm{N}^{\circ}$ 9, Amsterdam, Elsevier.

Edwards, S. y G. Tabellini (1991), "Explaining fiscal policies and inflation in developing countries", Journal of International Money and Finance, vol. 10, Amsterdam, Elsevier.
Evia, J.L., R. Laserna y S. Skaperdas (2008), "Socio-political conflict and economic performance in Bolivia", CESifo Working Paper Series, $\mathrm{N}^{\circ}$ 2249, Munich, CEsifo Group Munich.

Fausto, B. (1996), História do Brasil, São Paulo, Editora da Universidade de São Paulo (EDUSP).

Gurmu, S., P. Rilstone y S. Stern (1999), "Semiparametric estimation of count regression models", Journal of Econometrics, vol. 88, $\mathrm{N}^{\circ}$ 1, Amsterdam, Elsevier

Heston, A., R. Summers y B. Aten (2008), "Penn World Tables Version 6.1", Center for International Comparisons at the University of Pennsylvania [en línea] http://pwt.econ.upenn. edu/.

Maddison, A. (2008), The World Economy: Historical Statistics, París, Centro de Desarrollo de la ocDE [en línea] http://www. ggdc.net/maddison/.

Montellato, A., C. Cabrini y R. Catelli Jr. (2000), História temática: o mundo dos cidadãos, São Paulo, Ed. Scipione.

Muñoz, R. (2009), "Political instability and economic growth: the case of Venezuela (1983-2000)", Documentos de Trabajo, Caracas, Universidad Católica Andrés Bello.

Noronha, E.G. (2009), "Ciclo de greves, transição política e estabilização: Brasil, 1978-2007”, Lua Nova, N 76, São Paulo.

Rogoff, K. y C. Reinhart (2011), "From financial crash", American Economic Review, vol. 101, $\mathrm{N}^{\circ}$ 5, Nashville, Tennessee, American Economic Association.

Rogoff, K. y A. Sibert (1988), "Elections and macroeconomic policy cycles", Review of Economic Studies, vol. 55, N ${ }^{\circ} 1$.

Schulz, J. (1994), O Exército na política: origens da intervenção militar, 1850-1894, São Paulo, Editora da Universidade de São Paulo (EDUSP).

Seidl, E. (2010), "A formação de um exército à brasileira: lutas corporativas e adaptação institucional", História, vol. 29, $\mathrm{N}^{\circ}$ 2, São Paulo.

Simão, A. (1981), Sindicato e Estado. Suas relações na formação do proletariado de São Paulo, São Paulo, Editora Ática.

Solimano, A. (2003), "Governance crisis and the Andean Region: a political economy analysis", Macroeconomía del desarrollo, $\mathrm{N}^{\circ} 23$ (LC/L.1860-P), Santiago de Chile, Comisión Económica para América Latina y el Caribe (CEPAL). Publicación de las Naciones Unidas, $\mathrm{N}^{\circ}$ de venta: E.03.II.G.33.

Woo, J. (2005), "Social polarization, fiscal instability and growth", European Economic Review, vol. 49, № 6, Amsterdam, Elsevier. 